\title{
Spatial patterns of cultural tourism in Portugal
}

\author{
Alexandre Sousa Guedes ${ }^{\mathrm{a}, *}$, M. Isabel Martín Jiménez ${ }^{\mathrm{b}}$ \\ a Department of Economy, Sociology and Management, University of Trás-os-Montes and Alto Douro, Portugal \\ b Department of Geography, University of Salamanca, Spain
}

\section{A R T I C L E I N F O}

\section{Article history:}

Received 15 June 2015

Received in revised form 16 July 2015

Accepted 20 July 2015

Available online $\mathrm{xxxx}$

\section{Keywords:}

Spatial patterns

Cultural attractions

Package tours

Clusters

Peripheral areas

Portugal

\begin{abstract}
A B S T R A C T
This paper analyzes recurrent spatial patterns that characterize package holidays for mainland Portugal by applying a cluster analysis to cultural attractions and the number of overnight stays assigned to each municipality. The empirical results show that organized tourist programs based on cultural heritage break reduce to some extent the asymmetry of the spatiality of the Portuguese tourism model that historically was concentrated around the Algarve. This research shows that the articulation of nodes and their Euclidean distance in the analyzed programming models does not have a deterministic relationship with geographical and physical proximity. Rather the analysis unravels cumulative attraction patterns based on a hierarchical network topology that drains tourism from strategic gateways (Lisbon and Oporto) to peripheral municipalities.
\end{abstract}

(c) 2015 Elsevier Ltd. All rights reserved.

\section{Introduction}

The exhaustion of modernism's "aggregating differentiation" (living together in separate worlds) coincides with the emergence of a new cycle of "unifying breakdown" (living apart in the same world) (Fortuna, 1999, pp. 20-21) which is consistent with the assertion of "diversity and difference as liberating forces in redefining the cultural discourse" (PRECIS 6 as cited in Harvey, 1989, p. 9). The new ideological current (postmodernism) manifests itself as a clear reaction to modernism by stating individualization, pluralism and cultural fragmentation (Lash \& Urry, 1987). These changes triggered economic transitions to economies of scope supported on spatial clustering of economic activities as argued by Swyngedouw (1986) in order to provide individualized and differentiated responses as opposed to a universal and mass model.

The reversal of the previous logic that focused on rational tourism production methods to refocus on consumption and culture (Britton, 1991 ) sets forth new opportunities of recovery and repositioning of countries that based their tourism development paradigm on monolithic and highly concentrated spatial patterns (the case of Portugal).

The maturing of tourism originated the emergence of new supply segments in different niche markets (Richards, 1997, p. 7) by creating opportunities out of culture to the tourism industry (Smith, 1988). This process led to the spread of tourism into new geographies, giving rise to "various cultural particularisms and heterogeneities" (Fortuna,

\footnotetext{
* Corresponding author at: Rua Jaime Campos, Lote 5, Bloco E, 3. ${ }^{\circ}$ Esq., 5000-436 Vila Real, Portugal.

E-mail addresses: aguedes@utad.pt, alexandreguedes@msn.com (A.S. Guedes), imaji@usal.es (M.I.M. Jiménez).
}

1999, p. 12). The territory is thus the element where culture and tourism bond, founding cultural tourism which according Narhsted (as cited in Richards, 1997, p. 26) is a postmodern phenomenon. The cultural content of spaces acts as markers (Culler, 1981; MacCannell, 1976) for the tourism experience and a reagent for identity differentiation in a growing fragmented and competitive tourism environment (Ritchie \& Crouch, 2000).

Despite the intense spread of tourist destinations based on cultural heritage (Richards, 1997, p. 4) these seem to be subject to selection by tour operators and visitors, based on "the power of attraction of the tourist attractions" (Seguí-Llinás \& Capellà-Cervera, 2006, p. 234). Although the implosion of vertical differentiation between high and popular culture has been a trend of post-modernism (Hall, 1994; Urry, 1990), tourism tends to apply semiotic mechanisms that bifurcate the importance and authentication value of cultural resources (e.g. World Heritage Sites meaning "genuine"). This action is evident in the use of "cool" authentication mechanisms of cultural resources which is formally granted by certification (Cohen \& Cohen, 2012, p. 1298) (e.g. UNESCO heritage classification). Thus the importance of cultural resources as generators of tourism is set clear but also their capacity to regulate tourism spatial patterns by influencing choice. Moreover, the level of tourism seems to be also depending on the functional topology of spaces (concept applied to transport networks) (Rodrigue, Comtois, \& Slack, 2006) and specifically of tourism destinations (Baggio, Scott, \& Cooper, 2010). This issue involves the combination of cultural attractions (nodes according to Pearce, 1987) within spatial circuits (links). Hence it seems that cultural morphology of spaces is an asset that is a determinant to the expansion of capillary circuits that consolidate tourism within a destination as well as being able to reach more peripheral 
spatial units. According to Cluzeau (1998) tourism can often develop from more attractive and renowned poles to surrounding territories (and resources).

Lue, Crompton and Fesenmaier (1993, p. 297) use the concept of "cumulative attraction" to point out the relevance of tourist attractions as a leveraging element of tourism in a given space, a notion developed in the retailing milieu studies (Nelson, 1958) and applied to tourism (Fesenmaier \& Lieber, 1987; Kitamura, 1984). Cumulative attraction means that the clustering of attractions in multi-destination patterns provides a critical mass that is not provided by individual entities (Lue et al., 1993). This idea dates back to Gunn (1972) and Leiper (1979)) who argue that tourist attractions can be analyzed in terms of the spatial distribution of sites of interest. This analysis, which seeks to clarify the importance of the spatial structure of complementary opportunities in tourism, shows a particular interest in how visiting patterns are influenced by the tourism industry, i.e. by tour operators (Mansfeld, 1990; Seguí-Llinás \& Capellà-Cervera, 2006). Therefore, the observation of tour operator programs can reveal topological paradigms of functional nature which are based on clustering of cultural attractions within a limited timeframe (e.g. package tours).

This study aims to analyze recurrent spatial patterns that characterize organized tourism packages for mainland Portugal by examining cultural tourist attractions and the number of overnights scheduled/ assigned to each municipality. The research seeks to recognize spatial patterns resulting from the combination of territorial units into clusters and recurring travel itineraries. These should represent an alternative to a polarized spatial outline that resulted from mass tourism since 1965 in Portugal, replicated in the Algarve after the construction of the international airport in Faro (Costa, 2005).

In the Portuguese case, a better understanding of the capillaries that link spatial units can reveal different mechanisms of integration. Moreover these linkages can uncover regional strategic opportunities that enable the repositioning of peripheral areas. Regional integration can have a regenerative impact on the social and economic fabric of the periphery.

\section{Methodology}

This study is based on a sample frame of tour operators that incorporate cultural resources in their package tours for mainland Portugal in varying degrees of expertise, thus supporting the theoretical generalization that seems to disclose "(...) a new centering of the subjects guided by the appreciation of the new cultural signs" (Fortuna, 1999, p. 25) and simultaneously reveal alternative corridors of tourism practices.

Bearing in mind the general framework that sustains this research, it is our purpose to assess the porosity of mainland Portugal regarding organized tourism programs that combine cultural resources. This analysis will allow to extrapolate spatial patterns that can suggest latent functional archetypes able to propel higher levels of "tourist irrigation" (Cluzeau, 1998, p. 71) with a less asymmetric territorial impact.

The data will be used in order to identify concentration spots (clusters) of cultural resources (classified and non-classified) and simulate neural networks of hierarchical structures of nationwide and of regional scope. Furthermore, it will allow to uncover recurrent and dominant spatial patterns that display complementary opportunities, based on the "cumulative attractions" concept as well as interdependence of geographical units with different programming time-spans assigned.

Tour operators are regarded as a relevant information source (Baloglu \& Mangaloglu, 2001) being referred to by various authors as formal sources (Goodall, 1990), interpersonal sources (Hsiesh \& O'Leary, 1993), external formal sources (Gitelson \& Crompton, 1983), commercial sources (Mill \& Morrison, 1985), overt induced II $^{1}$ (Gartner, 1993) and professional sources (Baloglu, 1997), capable of creating and changing

\footnotetext{
1 Material received through travel agents and tour operators.
}

Table 1

Sample of tour operators analyzed.

\begin{tabular}{lllrlr}
\hline $\begin{array}{l}\text { Inbound } \\
\text { markets }\end{array}$ & $\begin{array}{l}\text { Sample } \\
\text { frame } \\
\text { (tour operators) }\end{array}$ & $\begin{array}{l}\text { Sample } \\
\text { (tour } \\
\text { operators) }\end{array}$ & $\begin{array}{l}\text { Source for data } \\
\text { extraction (package } \\
\text { tours) }\end{array}$ & \\
\hline Italy & 123 & 28 & $23 \%$ & 125 & $38 \%$ \\
Germany & 312 & 24 & $8 \%$ & 57 & $17 \%$ \\
Spain & 126 & 13 & $10 \%$ & 57 & $17 \%$ \\
France & 141 & 18 & $13 \%$ & 48 & $15 \%$ \\
UK & 213 & 14 & $7 \%$ & 30 & $9 \%$ \\
The Netherlands & 71 & 6 & $8 \%$ & 13 & $100 \%$ \\
Total & 986 & 103 & $10 \%$ & 330 & $4 \%$ \\
\hline
\end{tabular}

destination images as well as inducing consumer decision-making (Gartner, 1993; Gartner \& Bachri, 1994; Reimer, 1990). These skills make tour operators a convenient and relevant data source for spatial analysis. Tour operators are selected from the six most important countries of origin for Portugal's inbound markets: the UK, Germany, Spain, France, Italy and The Netherlands.

A database provided by Turismo de Portugal (the Portuguese central public authority responsible for promotion, enhancement and sustainability of tourism activities) containing 986 companies is the sample frame. A non-random sample has been drawn reducing the initial list to 103 tour operators that were chosen as a result of content analysis. From this sample a total of 330 package tours provided a source for data extraction (Table 1 ).

All tour operators with poor information on Portugal and supplying basic and generic seaside resort vacations with a strong real estate purpose were excluded.

The selection of tour operators was based on package tours that capture mainland Portugal according to more fragmentary patterns, regarding the level of cultural and geographical immersion by assessing the spatial units and cultural attractions assigned. The selected companies operate generic and specialized tours (e.g. culture; nature; religion).

Thus, the cultural and heritage substrates (cultural attractions) that make up the basis of travel experience constitute an important element that is mostly shaped into a touring pattern that tends to integrate different geographical units (Enoch, 1996), with a deeper spatial and territorial impact. Touring phenomenon is relevant for this research due to its founding rational that intensifies and maximizes complementary opportunities (van der Heijden \& Timmermans, 1988) between spatial units, challenging the assembly of the various cultural attractions and spatial fragments involved.

Two variables are selected to analyze package tour content, namely: cultural attractions (resources) and the length of stay assigned to each municipality. The presence of cultural resources was screened on all programs. The geographical occurrence of package tours programs was captured by intercepting all municipalities that configured the travel itineraries.

The average length of stay assigned to each municipality was corrected and converted into a program intensity indicator $(\mathrm{ms}=$ $\mathrm{m} \times \mathrm{fs} \times 100)^{2}$ to compensate for data imbalances, taking into account that each travel program consists of a different set of municipalities, and thus generated incomparable arithmetic means. A punctuation of 0.5 was attributed to all municipalities visited as a way of distinguishing them from unscheduled (and thus not visited or unseen) geographical units (Guedes, 2014).

The extracted data was calculated by inbound market and converted into a matrix to perform an agglomerative hierarchical cluster analysis. To support the cluster analysis the Euclidean distance was used to measure the level of similarity (and/or dissimilarity) between subjects. To find the number of "natural" groups in the matrix data, we applied the R-squared criteria (Maroco, 2003) for judging the degree of difference between each cluster, in each operation of the algorithm, by calculating the ratio between the sum of squares and the total sum of squares for

\footnotetext{
$2 \mathrm{~m}$ : arithmetic mean; fs: relative frequency.
} 


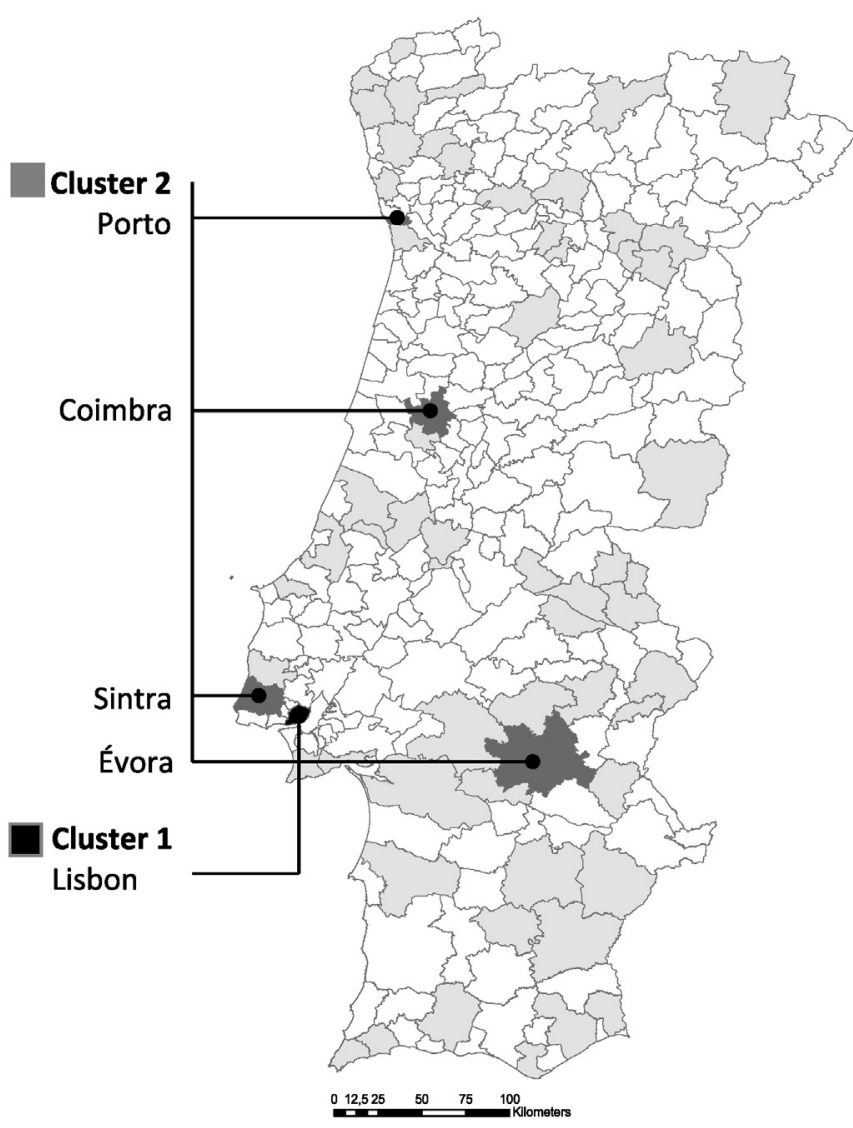

Cluster 3

\begin{tabular}{|c|c|c|}
\hline Batalha & Portalegre & Gavião \\
\hline Óbidos & Alcácer do Sal & Guarda \\
\hline Alcobaça & Ponte de Lima & Idanha-a-Nova \\
\hline Guimarães & Tavira & Leiria \\
\hline Tomar & Alter do Chão & Meda \\
\hline Braga & Barcelos & Mont.-o-Novo \\
\hline Vila Real & Ponte da Barca & Penedono \\
\hline Vila Viçosa & Sesimbra & Santi. do Cacém \\
\hline Mafra & Tarouca & SJ. da Pesqueira \\
\hline Lamego & V. do Alentejo & Setúbal \\
\hline Beja & Vila do Bispo & Vila Nova de Gaia \\
\hline Estremoz & Vila do Conde & \\
\hline Viseu & V. N. de Foz Côa & \\
\hline Elvas & Arraiolos & \\
\hline Ourém & Caminha & \\
\hline Amarante & Castro Marim & \\
\hline Castro Verde & Chaves & \\
\hline Valença & Faro & \\
\hline Bragança & Condeixa-a-Nova & \\
\hline Crato & R. de Monsaraz & \\
\hline Lagos & Serpa & \\
\hline Marvão & Viana do Castelo & \\
\hline Silves & Castelo de Vide & \\
\hline V. N. Barquinha & Mértola & \\
\hline
\end{tabular}

Fig. 1. Derived clusters from the list of National Monuments quoted by tour operators.

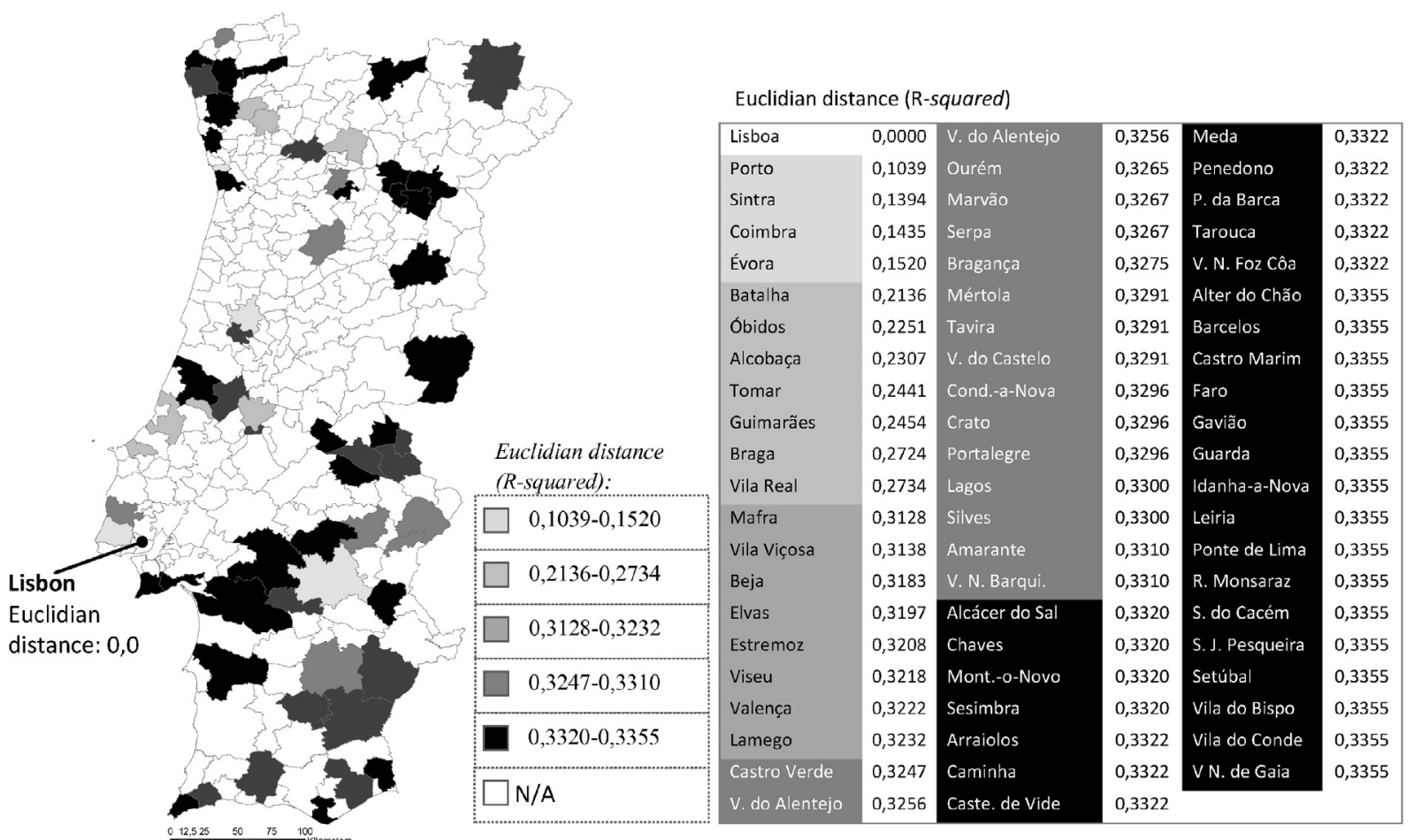

N/A - Not applicable 
each of the variables used in the analysis and stabilizing a number of clusters responsible for a significant proportion of the total variability (e.g. $>80 \%$ ).

The results were displayed on a map to exhibit complex paradigms of interdependence of geographical units taking into account their degree of association. The graphical projection also aims to recognize the gateways (static elements) which give access to the destination, displaying temporal binding levels between municipalities (dynamic elements) and identifying static elements such as cross nodes (hubs) and stopovers that perform a transitional role between destinations as well as acting as secondary destinations in longer routes (Rodrigue et al., 2006).

\section{Results}

3.1. Spatial patterns of cultural attractions identified in package tours: agglomerative hierarchical cluster analysis

On average, listed cultural attractions account for $73 \%$ of all observations per inbound market. Eighty percent of these attractions are "National Monuments" which represent $61 \%$ of all listed cultural attractions extracted from travel brochures per inbound market. The level of concentration of cultural attractions classified as "National Monument" per municipality, exhibits Lisbon (capital) at the top of this ranking, amounting to $23 \%$ on average per market of all cultural attractions quoted. Also, per market, $40 \%$ of all cultural attractions classified National Monuments are UNESCO cultural heritage sites.

Out of the ten municipalities whose cultural attractions were more cited by all tour operators nine possess UNESCO classified sites, which

\section{National inventory of classified cultural heritage}

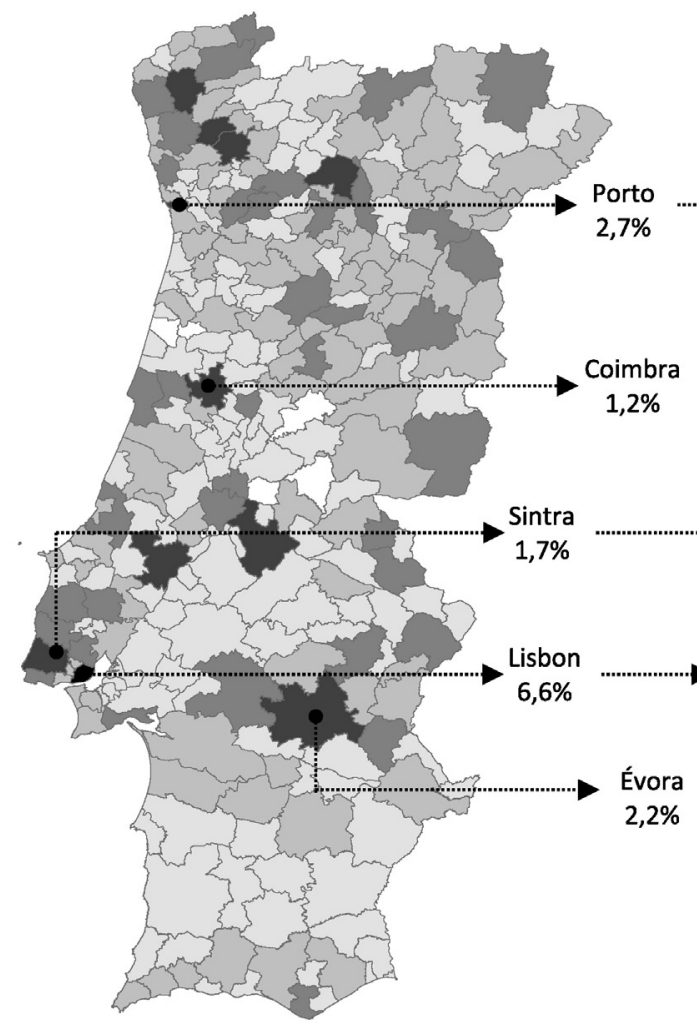

Source: DGPC (2014)

N/A - Not applicable; pp: percentual points totals 90\% of all World Cultural Heritage in Portugal. There seems to be a link between the level of spatial concentration of classified cultural heritage (National Monuments and UNESCO World Heritage Sites) and the itineraries/routes chosen by tour operators.

The performance of an agglomerative hierarchical cluster analysis by applying an algorithm of the shortest distance exhibits three clusters that have the same level of similarity within each group of subjects displayed by the six inbound tour operators. The analysis confirms a concentration trend of cultural heritage assets of greater value around Lisbon, which also adds approximately to $7 \%$ of all National Monuments in Portugal. Lisbon's capacity to capture interest and editorial attention within holiday packages planning for mainland Portugal plays an essential role in destination decision-making by displaying a morphological cultural substrate that enables Portugal to differentiate from other destinations. Lisbon is therefore a single cluster and represents an anchor that seems to allow, in a substantial number of cases, the source/starting point of variable geometry holiday proposals. Therefore it has a tourism primacy in mainland Portugal as it is the common denominator of all programs analyzed. A second group/cluster of geographical units (Sintra, Porto, Coimbra and Évora) is identified, also aggregating relevant cultural attractions of world importance (UNESCO classification). These cities act as triggers for an extended tourism experience that is established over a wider mesh of municipal units (59) that constitute the third cluster (Fig. 1).

The cluster analysis exhibits a hierarchical distribution of cultural attractions which translates into a range of grouped municipalities. The Lisbon cluster is placed at the top of this hierarchy combining the highest frequency of cultural attractions quoted by tour operators. In

\section{Classified cultural heritage quoted by tour operators}

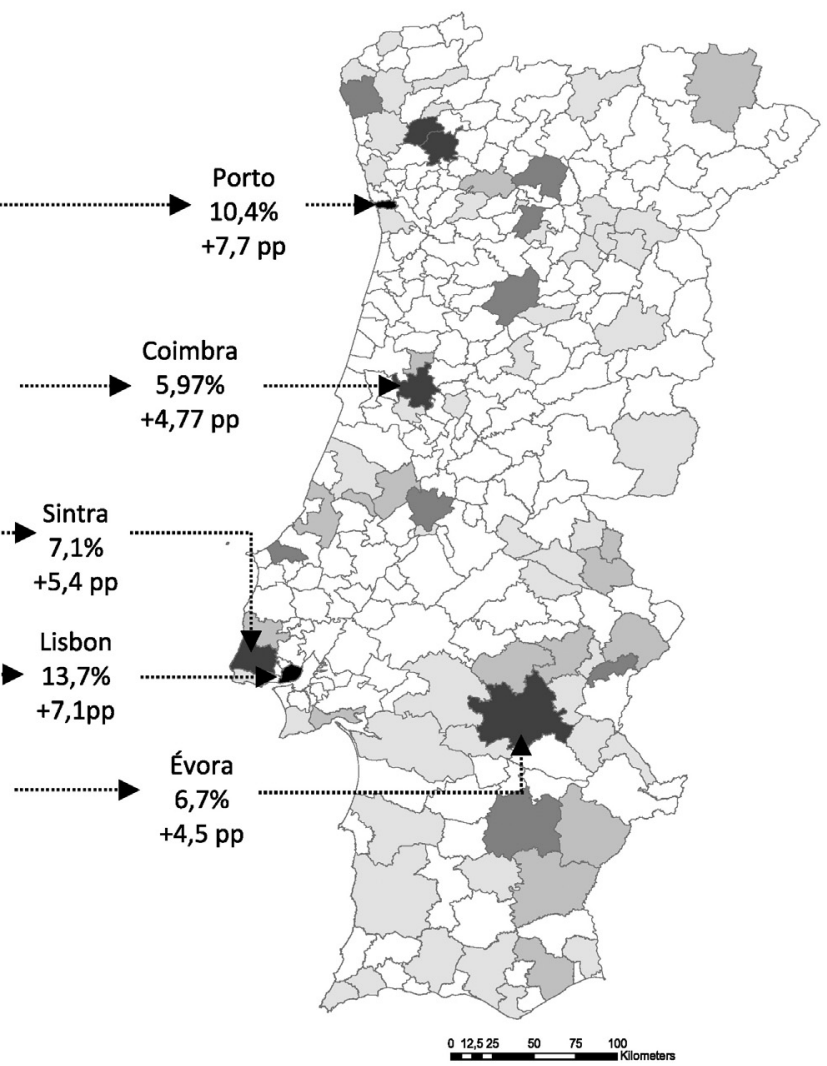

Fig. 3. Distribution of classified cultural heritage in mainland Portugal - national inventory versus classified cultural heritage quoted by tour operators. Source: Direção-Geral do Património Cultural (DGPC) (2014) 
most cases the capital is chosen as the point of departure for holiday programs to mainland Portugal. From here itineraries are designed and display a thinner capillary that intercept nodes that are located in the second and third clusters.

This relationship is illustrated by plotting the Euclidian distances that express the level of dissimilarity of all municipalities intercepted comparatively to Lisbon (Fig. 2). The results demonstrate that the combination of nodes and their Euclidean distance in the analyzed programming models are not consistent with an equivalent ratio of geographical and physical proximity. This inconsistency expresses the hierarchical structure of cultural resources in terms of selection by tour operators as well as cumulative attraction patterns combined with logistical requirements.

It is thus possible to observe the complexity of programming models, particularly in flow transmission patterns with a broad regional impact and a complex nature that seems to be triggered by Cluster I (Lisbon's cultural resources) and Cluster II, revealing a structural role in organized tourism planning for Portugal. These patterns display the transitional purposes of strategic gateways (Lisbon and Oporto) that perform a pivotal function by draining tourism to peripheral municipalities (Jansen-Verbeke, 2007). The study discloses a neural network with hierarchical levels of appropriation of cultural markers for the purpose of organized tourism. The Euclidean distances calculated from the relative frequency of National Monuments quoted by municipality confirm this network hierarchy.

Moreover, there seems to be a recurring tendency of tour operators to select a small fragment of mainland Portugal's cultural heritage (Fig. 3) as a consequence of the time-space frame that limits package tour design. This too seems to be influenced by capital accumulation and concentration of classified cultural resources around Lisbon and Oporto, the two major metropolitan centers in mainland Portugal where cultural power is more concentrated, following the same line of thought argued by Zukin (1991) when examining urban landscapes.
Program proposals expose intermediate/transitional municipalities (and cultural reservoirs) that seem to untie peripheral spatial units. That seems to be the role of Coimbra that performs as a gateway to secondary cultural destinations, as well as Sintra a node that could be assumed to be spatially subsidiary to Lisbon because of its geographical proximity. However, that is not the case. The Euclidian distance to Lisbon is greater than to Oporto which is further away. Thus, Sintra with a high level of concentration of National Monuments, assumes greater interest by tour operators as reveals the number of iterations in all holiday packages. Comparing the relative frequencies of National Monuments quoted by tour operators on the holiday packages, Sintra has a structure similar to Évora and Coimbra. The proximity to Lisbon leads, moreover, to a degree of programmatic association that tends to take advantage of UNESCO's insignia ("cool" authentication), whose convergence seems to be confirmed by the Euclidian distances to the third cluster municipalities of Batalha and Alcobaça. This reveals a tendency of tour operators to seek validation mechanisms of genuineness (Cohen \& Cohen, 2012, p. 1299) of destinations through a limited number of markers (attractions) that are internationally accredited (e.g. UNESCO), hence acting as a customer induction method.

By amplifying the analysis to all classified cultural heritage, Oporto has an autonomous performance, though different from Sintra, Coimbra and Évora. The empowerment of Oporto in a broader analysis confirms its administrative and economic relevance (second most important city in Portugal) as well as its dissimilarity in terms of cultural heritage due to its UNESCO classified historic center. Oporto exemplifies the kind of urban morphology that Ashworth and Tunbridge (2000, p. 9) describe as "(...) urban forms from the past that have survived into the contemporary city". By widening the study to "All classified cultural attractions" (Fig. 4), the fourth cluster displays a broader geographical influence, adding fourteen municipalities, when compared with cultural attractions classified as National Monuments. The morphological pattern

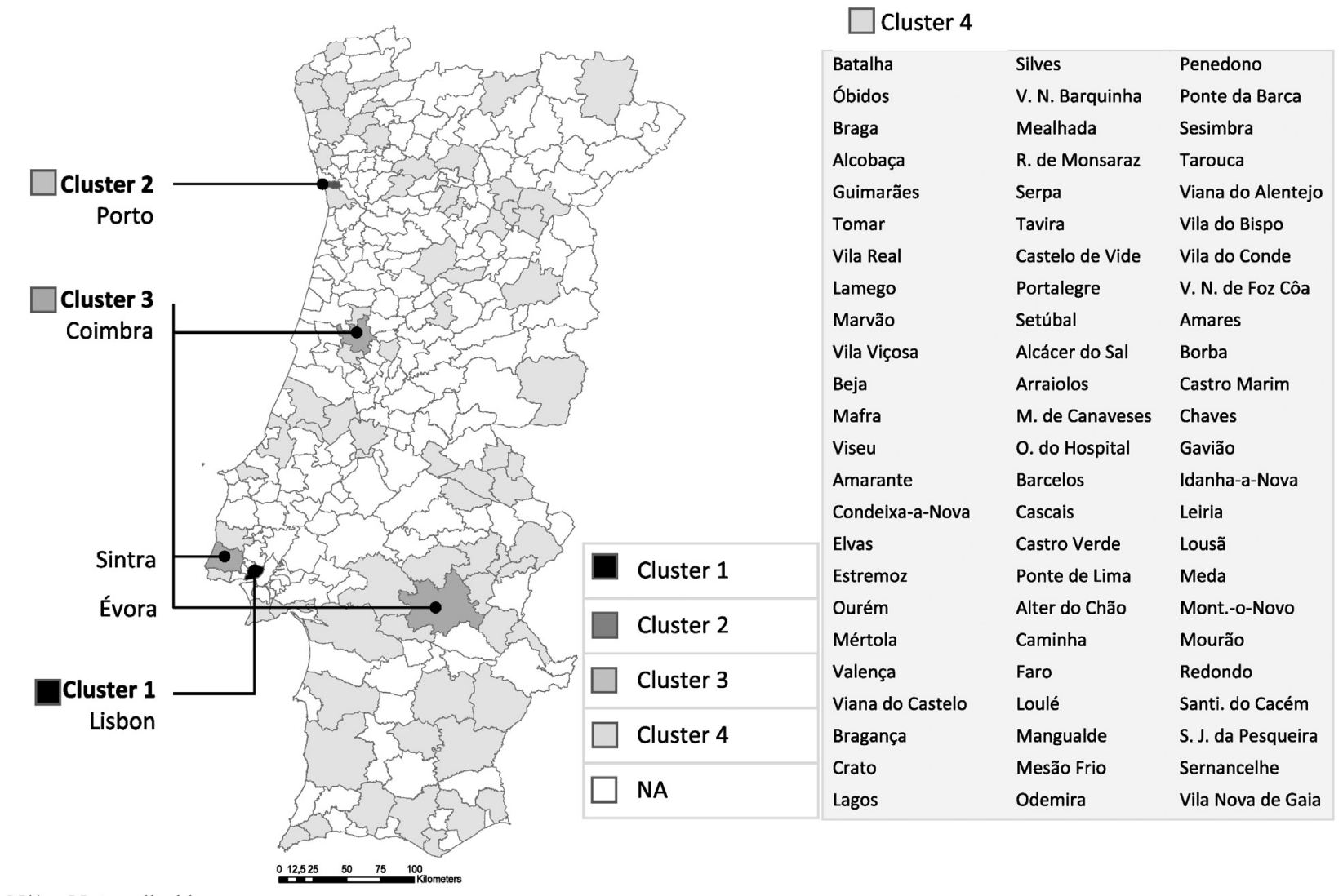

N/A - Not applicable

Fig. 4. Derived clusters from all classified cultural attractions extracted from package tours. 
does not change profoundly but reveals and emphasizes the presence of other intermediate and periphery regions that tend to be less marked by the tour operators.

The analysis confirms neural networks propelled by nodes (municipalities) that tend to federate and bind geographical areas through corridors that influence and shape spatial patterns of organized tourism.

3.2. Spatial patterns derived from the corrected average length of stay per municipality in package tours: agglomerative hierarchical cluster analysis

The analysis of the corrected average length of stay per municipality (programming intensity indicator) broadens the spatial analysis by adding 77 municipalities to those examined within the cluster analysis of cultural attractions. This geographical expansion is due to the fact that a considerable amount of municipalities are referred to as a point of interest without any explicit indication of cultural attractions. Others quote non-classified cultural resources as well as non-accurate references to cultural heritage (e.g. Aveiro is described as the "Venice of Portugal").

Lisbon confirms, once again, its centrality when examining the corrected average length of stay, exhibiting a hegemony displayed in the analysis of the levels of concentration of cultural attractions quoted in holiday programs. The intensity of programming is also influenced by the availability of accommodation in urban areas. Oporto, with its ample supply of accommodation, asserts itself as a major urban destination in mainland Portugal.
Oporto also stands out for possessing a logistics (e.g. international airport) infrastructure that allows tour operators to develop a more robust action, asserting this municipality as an important tourism gateway for mainland Portugal, ranking after Lisbon. It is also a strategic hub with a transience and intermediation purpose, establishing a level of connectivity with spatial units grouped in the third cluster which is the most homogeneous group of subjects displaying greater similarity between elements. Oporto seems therefore to guarantee a similar functional performance as Lisbon but in a more confined regional context. Being simultaneously an important node of conjunction with Lisbon it exerts a significant action as a strategic hub to the North of mainland Portugal by connecting to third-level nodes (Cluster III) and allowing a regional interchange of tourism flows and operations (Fig. 5).

The examination of spatial patterns and itineraries set up by tour operators (Fig. 6) exhibit three prevalent multi-destination models that follow those outlined by Lue et al. (1993). The first two have a common root that lies on the trip chaining pattern, differing from one another by the presence of one or two portals/gateways of entry and exit of mainland Portugal. These multi-destination shapes are typical of an itinerant route identified in the Anglo-Saxon literature as touring and also common in package tours. The third model that was identified is the base camp or radial pattern, which has a centripetal outline and is used, typically for logistics reasons, concentrating overnights in one geographical node. Also the trip chaining variant (models I and II) pattern shows possible combinations with other models that result mainly from strict limitations of the program scope as well as morphology and logistics

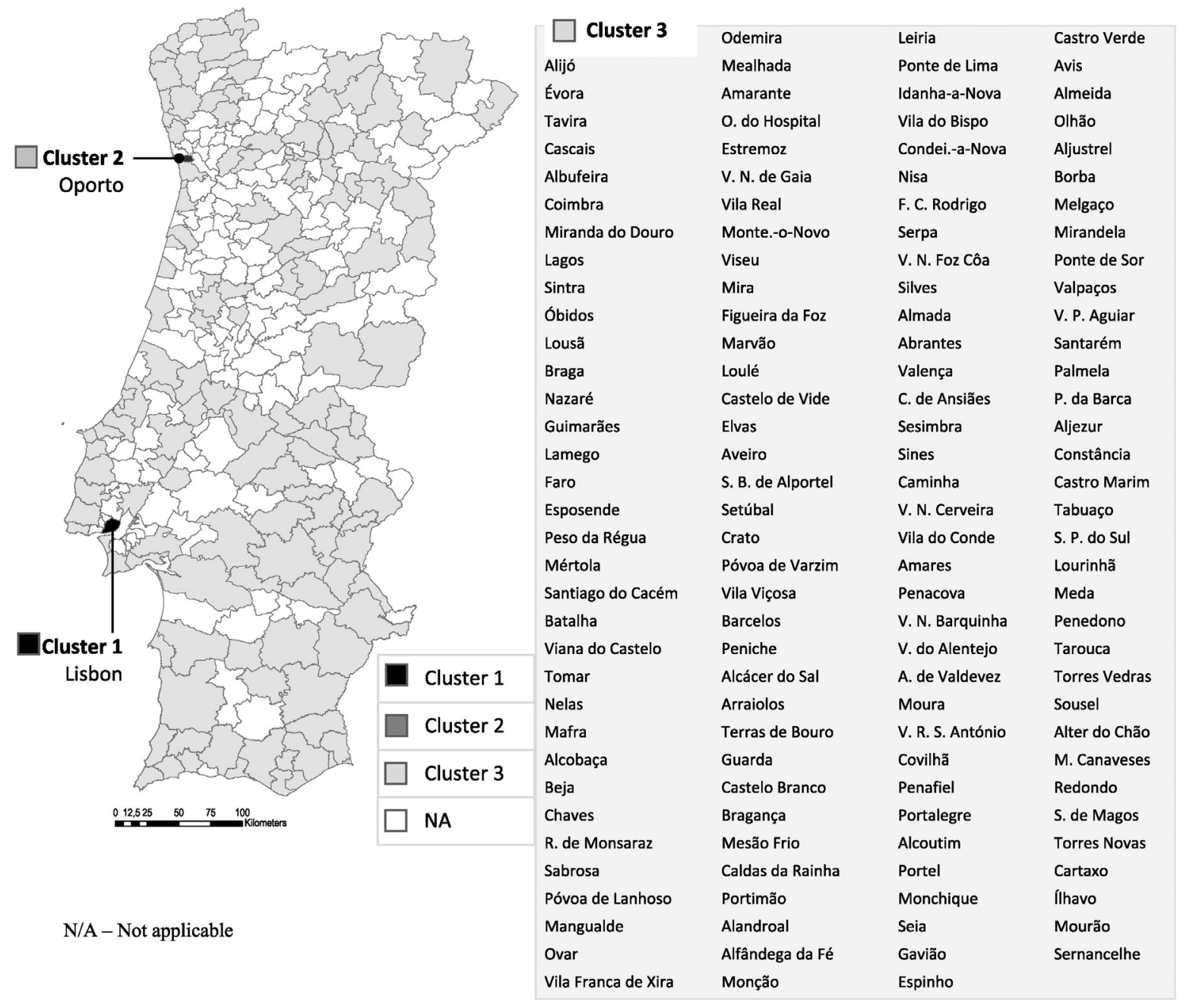

Fig. 5. Derived clusters from the corrected average length of stay per municipality assigned by tour operators. 
restrictions which tend to confine holiday packages around a marquee space that provides accordable distances to the time-span available to perform the package tour.

These two models (model I and II) assume combinations and sequences of nodes that exhibit a hierarchical structure of municipalities based on the cluster analysis of the programming intensity indicator. Two nodes are ranked up the list of quoted municipalities, Lisbon and Porto, which are recurring portals/gateways of entry-exit to mainland Portugal. Models I and II show a similar structure with respect to the trip chaining pattern. However, they are distinct because they have a different number of gateways. The first model exhibits two different portals/gateways, one that accesses the destination and one that provides the exit. The second pattern displays one single portal of entrance-exit to the destination, which normally coincides with Lisbon. This model, which tends to be the most common, can be observed in all of the inbound markets examined in longer and high longitude routes that cover in most cases, a large fraction of mainland Portugal but also observed in shorter regional tours (Fig. 6).
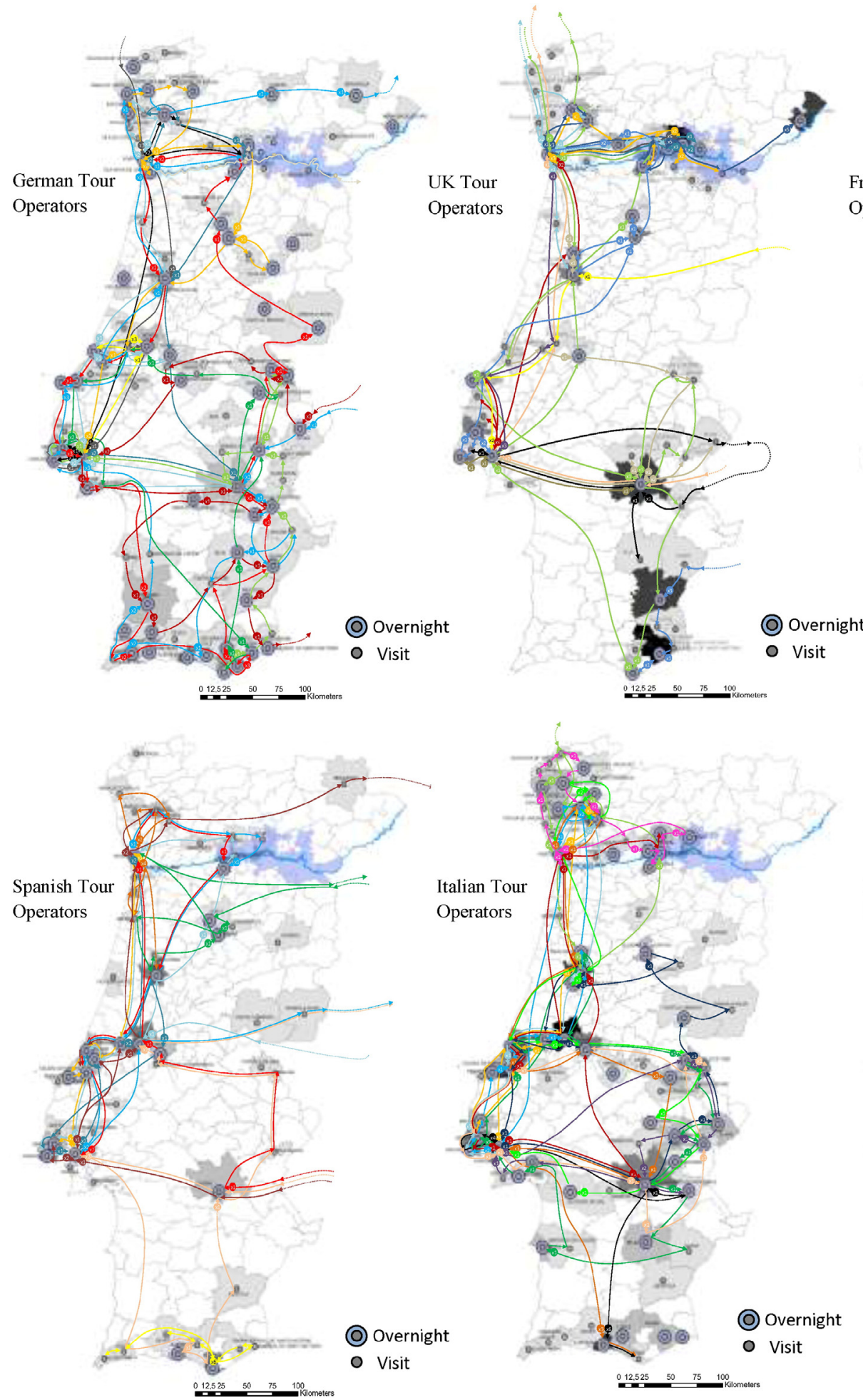
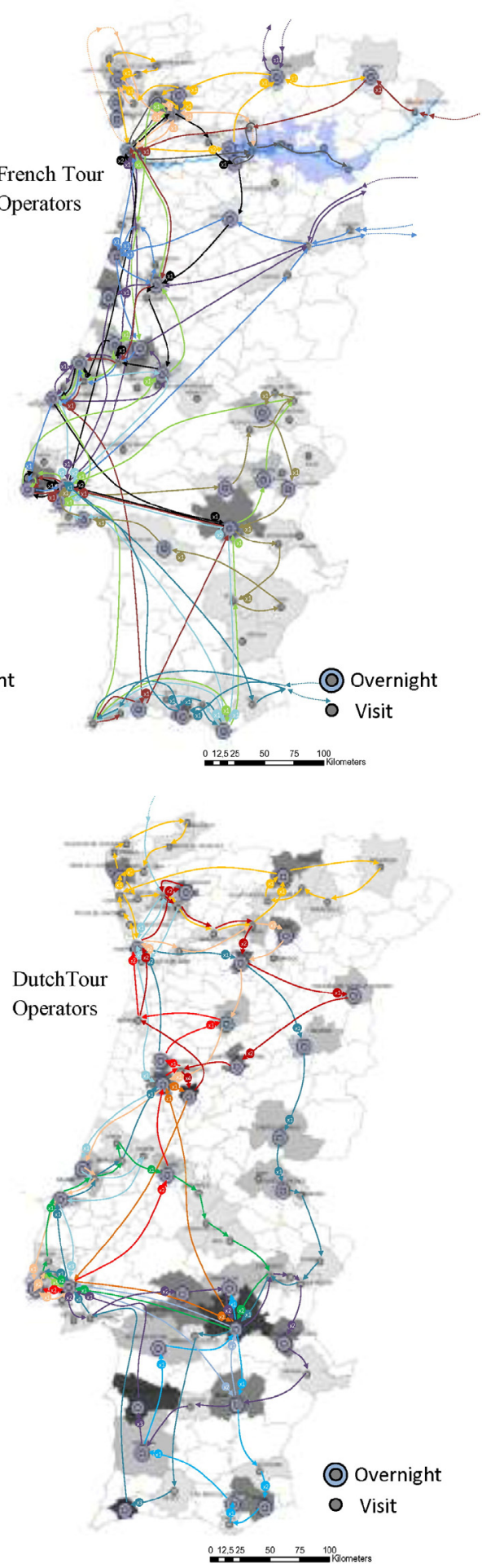

Fig. 6. Spatial patterns of analyzed holiday programs from Germany, Spain, France, The Netherlands, Italy and the UK. 
The trip chaining model can also be observed in combination with model III - base camp or radial (Lue et al., 1993). Base camp or radial patterns appoint a center/base node from which other satellite nodes/ destinations are intersected and visited. These secondary spatial units usually lack logistical assets (e.g. accommodation) able to amplify tourism operations and some do not withhold cultural resources able to assert themselves as higher ranked node in terms of programming intensity.

Also, the radial pattern may occur in circumstances where programming tends to have a particular thematic focus, as occurs with Ourém (Fátima), the religious center that has generated a concentrated tourism pattern. In the radial model, the master node often coincides with the portal/gateway of entry-exit of the destination and combined with the trip chaining model. This pattern can be observed in some cases which combine itineraries around Lisbon and Oporto or in frequent circumstances around Nelas, Faro and Ourém (Fig. 6).

The study exhibits a trend of specialization of tourism around certain areas/regions that are known for particular themes that motivate travel and tourism (e.g. Fátima - Religious tourism; Douro valley - Wine and Nautical Tourism) frequently connected with peripheral geographical regions. This spatial pattern can be observed around Oporto which tends to establish connectivity with the peripheral Douro valley, or around Lisbon that interconnects with low density areas such as the Alentejo region.

The study uncovers a set of spatial patterns and circulation corridors that configure a neuronal network that is planned by tour operators by exalting a set of endogenous resources and integrating crucial logistical infrastructures which grant an articulated mobilization that translates into dominant itineraries.

\section{Conclusions}

Organized tourism programs based on cultural heritage break and reduce to some extent the asymmetry of the spatiality of Portuguese tourism model, historically concentrated around the Algarve. By applying a cluster analysis to cultural attractions and corrected average length of stay per municipality assigned by tour operators in travel brochures in six relevant inbound markets, spatial patterns have been discerned.

The analysis shows a hierarchical and polarized neuronal network around Lisbon. On the other hand, tourism is penetrating the periphery, which induces opportunities for mainland Portugal to qualify and amplify itself as an international tourism destination. Opening-up of the interior to international tourism may contribute to the social and economic recovery of peripheral areas plagued by demographic decline (Nash \& Martin, 2003).

The observed programming patterns display, typically, a circular outline but always according to a sequential nexus that results from the connection of nodes from portals that have a strategic role in the unblocking of peripheral areas of higher tourist opacity. The analysis confirms neural networks propelled by nodes that tend to federate geographical units that are linked by corridors that enable dissimilar levels of spatial immersion (e.g. Lisbon - Oporto; Oporto - Douro region).

The level of concentration of holiday programs around a limited number of nodes also conceals a certain "existential dilemma" (Dann, 1999, p. 178) associated with the search/election of genuine sites that have not changed and that are both comfortable, providing convergence of "timelessness with a time limit" (Willis as cited in Dann, 1999, p. 178). Programming and planning package tours must tackle the logistics issue, which also determines the level of tourist immersion to peripheral areas. This means that the neural network described through cultural heritage morphology can be transformed by infrastructural adjustment, which can enable lengthier stays.

This research also shows that the articulation of nodes and their Euclidean distance in the analyzed programming models does not have a deterministic relationship with geographical and physical proximity. This demonstrates the hierarchical structure of cultural resources in terms of selection by tour operators as well as cumulative attraction patterns articulated with logistics requirements. There seems to be a close spatial relation between cultural attraction density, particularly classified cultural heritage (National Monuments and UNESCO World Heritage Sites), logistics and tourism.

Finally this study uncovers modeling parameters of cultural morphology with a broader spatial impact of tourism on mainland Portugal by incorporating low density areas which expose possible territorial cohesion opportunities. This suggests that enabling organized tourism to play an effective role through cultural resources transformation into cultural attractions with economic value (Billington et al., 1991) could induce and trigger social, demographic and cultural sustainability of peripheral areas.

\section{References}

Ashworth, G., \& Tunbridge, J. (2000). The tourist-historic city: Retrospect and prospect of managing the heritage city. Oxford: Elsevier Science Ltd.

Baggio, R., Scott, N., \& Cooper, C. (2010). Network science: A review focused on tourism. Annals of Tourism Research, 37(3), 802-827.

Baloglu, S. (1997). The relationship between destination images and sociodemographic and trip characteristics of international travelers. Journal of Vacation Marketing, 3(3), 221-233.

Baloglu, S., \& Mangaloglu, M. (2001). Tourism destination images of Turkey, Egypt, Greece and Italy as perceived by US-based tour operators and travel agents. Tourism Management, 22(1), 1-9.

Billington, R., et al. (1991). Culture and society: A sociology of culture. Hampshire: Macmillan Education.

Britton, S. (1991). Tourism, capital and place: Towards a critical geography of tourism. Environment and Planning D: Society and Space, 9(4), 451-478.

Cluzeau, C. (1998). Le tourisme culturel. Paris: Presses Universitaires de France.

Cohen, E., \& Cohen, S. (2012). Authentication: Hot and cool. Annals of Tourism Research 39(3), 1295-1314

Costa, C. (2005). Turismo e cultura: avaliação das teorias e práticas culturais do sector do turismo (1990-2000). Análise Social, XL(175), 279-295.

Culler, J. (1981). Semiotics of tourism. The American Journal of Semiotics, 1(1/2), 127-140.

Dann, G. (1999). Writing out the tourist in space and time. Annals of Tourism Research, 26(1), 159-187.

Direção-Geral do Património Cultural (DGPC) (2014, April 27). Património cultural Pesquisa de património imóvel (Retrieved April 27, 2014, from: http://www patrimoniocultural.pt/pt/patrimonio/patrimonio-imovel/pesquisa-do-patrimonio/ classificado-ou-em-vias-de-classificacao/geral/).

Enoch, J. (1996). Contents of tour packages: A cross-cultural comparison. Annals of Tourism Research, 23(3), 599-616.

Fesenmaier, D., \& Lieber, S. (1987). Outdoor recreation expenditures and the effects of spatial structure. Leisure Sciences: An Interdisciplinary Journal, 1(9), 27-40.

Fortuna, C. (1999). Identidades, percursos, paisagens culturais: Estudos sociológicos de cultura urbana. Oeiras: Celta Editora.

Gartner, W. (1993). Image formation process. Journal of Travel \& Tourism Marketing, 2(3), 191-212.

Gartner, W., \& Bachri, T. (1994). Tour operators' role in the tourism distribution system: An Indonesian case study. Journal of International Consumer Marketing, 6(3/4) 161-179.

Gitelson, R., \& Crompton, J. (1983). The planning horizons and sources of information used by pleasure vacationers. Journal of Travel Research, 21(3), 2-7.

Goodall, B. (1990). How tourists choose their holidays: An analytical framework. In B. Goodall, \& G. Ashworth (Eds.), Marketing in the tourism industry: The promotion of destination regions (pp. 1-17). London: Routledge.

Guedes, A. (2014). O domínio cultural no turismo organizado - o caso português: Da polarização territorial à valorização endógena e local. Doctoral dissertation Salamanca: University of Salamanca (Retrieved from http://hdl.handle.net/10366/125214).

Gunn, C. (1972). Vacationscape: Designing tourist regions. Austin: University of Texas.

Hall, C. (1994). Tourism and politics: Policy, power and place. Chichester: John Wiley \& Sons

Harvey, D. (1989). The condition of postmodernity: An enquiry into the origins of cultural change. Cambridge MA \& Oxford UK: Blackwell.

Hsiesh, S., \& O'Leary, J. (1993). Communication channels to segment pleasure travelers. Journal of Travel \& Tourism Marketing, 2(2/3), 57-75.

Jansen-Verbeke, M. (2007). Cultural resources and the tourismification of territories. Acta Turistica Nova, 1(1), 21-41.

Kitamura, R. (1984). Incorporating trip chaining into analysis of destination choice. Transportation Research Part B, 18, 67-81.

Lash, S., \& Urry, J. (1987). The end of organized capitalism. Cambridge: Polity Press.

Leiper, N. (1979). The framework of tourism: Towards a definition of tourism, tourist, and the tourist industry. Annals of Tourism Research, 6(4), 390-407.

Lue, C., Crompton, J., \& Fesenmaier, D. (1993). Conceptualization of multi-destination pleasure trips. Annals of Tourism Research, 20, 289-301.

MacCannell, D. (1976). The tourist: A new theory of leisure class. Berkley: University of California Press.

Mansfeld, Y. (1990). Spatial patterns of international tourist flows: Towards a theoretical framework. Progress in Human Geography, 14(3), 372-390.

Maroco, J. (2003). Análise estatística: Com utilização do SPSS. Lisboa: Edições Sílabo. 
Mill, R., \& Morrison, A. (1985). The tourism system: An introductory text. New Jersey: Prentice-Hall.

Nash, R., \& Martin, A. (2003). Tourism in peripheral areas - the challenges for northeast Scotland. International Journal of Tourism Research, 5, 161-181.

Nelson, R. (1958). The selection of retail locations. New York: F. W. Dodge Corporation.

Pearce, D. (1987). Spatial patterns of package tourism in Europe. Annals of Tourism Research, 14(2), 183-201.

Reimer, G. (1990). Packaging dreams: Canadian tour operators at work. Annals of Tourism Research, 17(4), 501-512.

Richards, G. (1997). Cultural tourism in Europe. Wallingford, Oxon: Cab International.

Ritchie, J., \& Crouch, G. (2000). The competitive destination: A sustainability perspective. Tourism Management, 21(1), 1-7.

Rodrigue, J., Comtois, C., \& Slack, B. (2006). The geography of transport systems. Oxon: Routledge.

Seguí-Llinás, M., \& Capellà-Cervera, J. -E. (2006). Spanish package holiday tourism to China: Spatial patterns and tourist attractions. Tourism Geographies: An International Journal of Tourism Space, Place and Environment, 8(3), 233-252.

Smith, S. (1988). Defining tourism: A supply-side view. Annals of Tourism Research, 15(2) 179-190.

Swyngedouw, E. (1986). The social-spatial implications of innovations in industria organization. Working paper 20. Lille: Johns Hopkins European Center for Regional Planning and Research.

Urry, J. (1990). The tourist gaze. London: Sage Publications.

van der Heijden, R., \& Timmermans, H. (1988). The spatial transferability of a decompositional multi-attribute preference model. Environment \& Planning A 20(8), 1013-1025.

Zukin, S. (1991). Landscapes of power: From Detroit to Disney World. Berkeley: University of California Press.

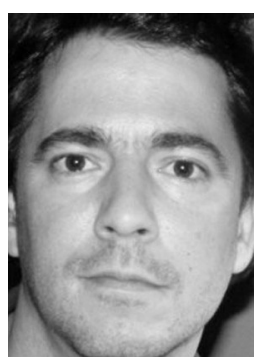

Alexandre Sousa Guedes First author. Alexandre Guedes is senior technician at the Porto and the North of Portugal DMO and invited lecturer at the University of Trás-osMontes and Alto Douro (Vila Real, Portugal) and Portucalense University (Porto, Portugal). He holds a degree (BSc) in Tourism Management and Planning (University of Aveiro, Portugal), a master's degree in Heritage and Tourism (University of Minho, Portugal) and a PhD in New Resources and Sustainability in Tourism (University of Salamanca). His research interests include tourism geography, tourism planning, spatial analysis, cultural tourism, wine tourism and river tourism.

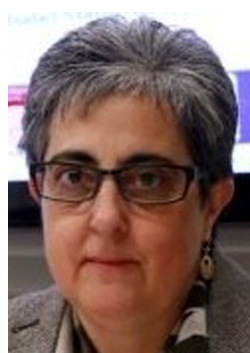

Ma. Isabel Martín Jiménez Co-author. M. Isabel Martín Jiménez is lecturer in the Department of Geography at the University of Salamanca (USAL), Spain. She holds a PhD in Geography at the same university and has led and participated in several research projects related to both spatial planning and regional development, with special attention to rural areas and the economic value of their cultural and natural heritage through tourism development. As a teacher she has taught at various doctoral programs in Columbia and Portugal focusing on tourism resources and their sustainability. 